\title{
Open Ocean
}

\section{Here Be Dragons 2018}

\section{Report}

Katy Croff Bell ${ }^{1}$ Jenni Chow ${ }^{2}$ Alexis Hope ${ }^{2}$ Dan Novy ${ }^{2}$

${ }^{1}$ MIT Media Lab \& National Geographic Society, ${ }^{2}$ MIT Media Lab

Published on: Oct 01, 2021

DOI: https://doi.org/10.21428/a680be9a.207c346e

License: Creative Commons Attribution 4.0 International License (CC-BY 4.0). 
In February 2018, Open Ocean convened 200 explorers, innovators, artists, scientists, and storytellers in collaboration with the National Geographic Society at an event called Here be Dragons. Our goal was to identify the uncharted territories that still exist in ocean exploration and storytelling. The event consisted of one day of panel discussions and lightning talks by a wide array of ocean experts, and one day of collaborative project development, culminating in pitches for project funding. Of the thirteen proposals received, eight projects were selected for funding; the projects ranged from immersive storytelling exhibitions to AI-driven data analysis to collaborative capacity development. All projects were presented at the 2018 National Ocean Exploration Forum: All Hands on Deck in November 2018, less than a year after their conception.

The lasting impact of Here Be Dragons extends far beyond the projects conceived there. This event involved individuals from beyond traditional academic oceanography, sparking new ideas and creating agency among the participants to feel involved in ocean exploration solutions. A new movement was launched at Here be Dragons, one that looks to radical and creative solutions to accelerate the pace of deep sea discovery and storytelling.
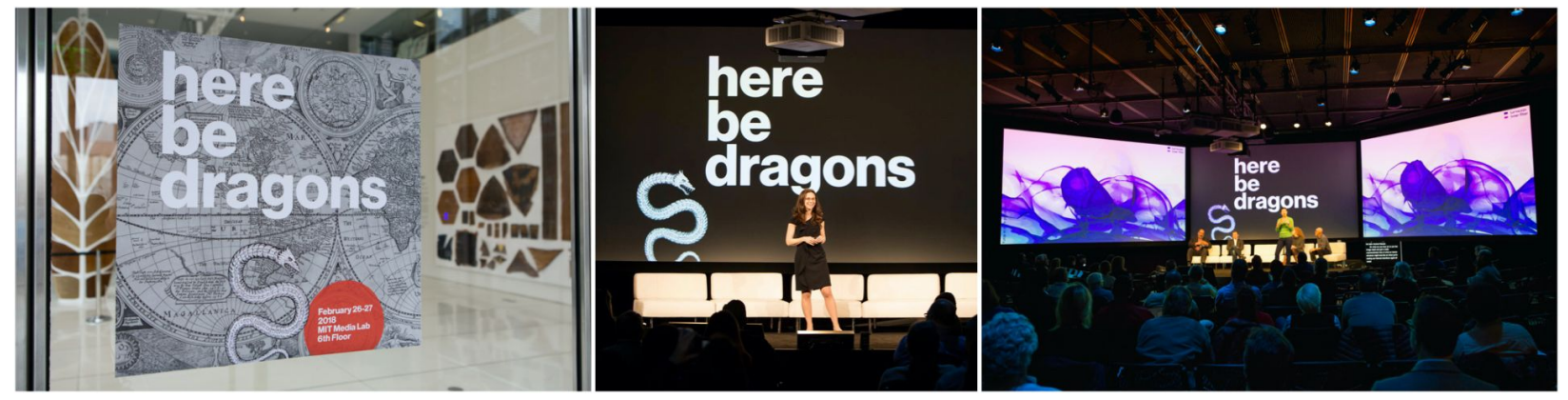

Figure 1

L-R: Dr. Katy Croff Bell welcomes Here be Dragons participants. Dr. Kakani Katija discusses the importance of carbon flux to the deep sea.

\section{Introduction}

Sea monsters such as the kraken, prister, and rosmarus indicated uncharted territory on elaborate new maps of the world in medieval times. Despite many advances in mapping technology and data acquisition in the last 500 years, our ocean remains largely uncharted and poorly understood. 
Here be Dragons convened more than 200 explorers, innovators, artists, scientists, and storytellers to identify the uncharted territories that still exist in ocean exploration and storytelling. In response, MIT students and explorers worked together to develop and present collaborative projects to deploy new and emerging technologies in the field that address gaps in our understanding and sharing of the ocean. Select proposals were funded for Rapid Field Deployments.

Here be Dragons took place at the MIT Media Lab and New England Aquarium Monday, February 26, and Tuesday, February 27, 2018, in collaboration with the National Geographic Society.
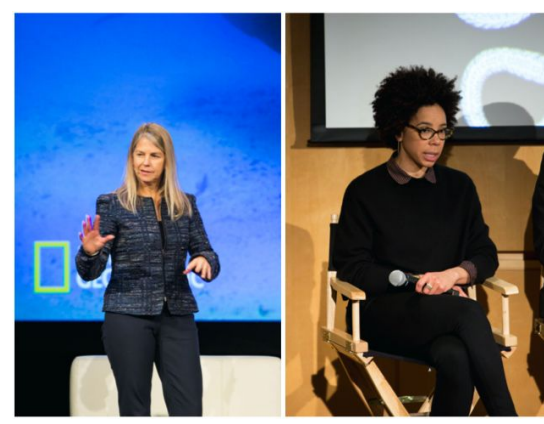

L-R: Dr. Dava Newman,
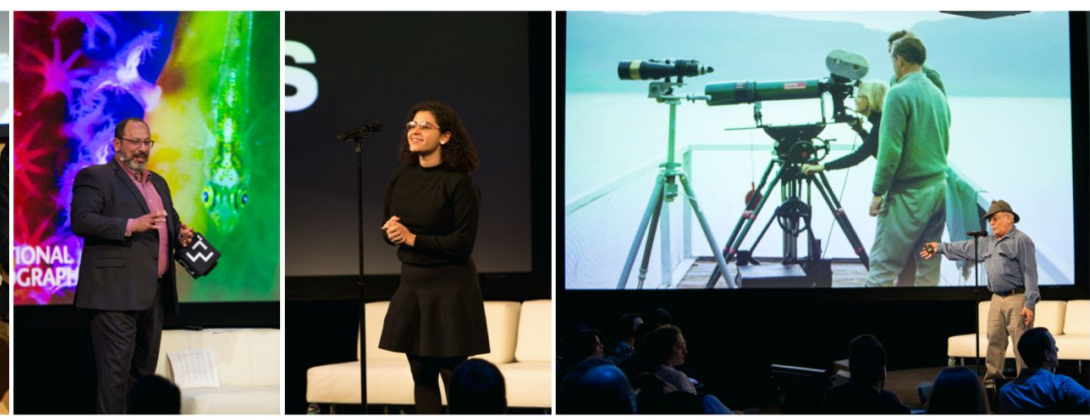

Figure 2

Ayana Elizabeth Johnson, Dr. Pete Girguis, Devora Najjar, Martin Klein.

\section{About the Event}

\section{Day 1: What is your dream for the ocean?}

The first day of the event was dedicated to short talks and panel discussions on six themes: Exploration and Discovery; Data Analysis and Sharing; Sea Stories; Our Thriving Ocean; Platforms and Sensors; and Democratizing the Ocean. Speakers were challenged with discussing the biggest gaps in their fields of study, as well as their dreams for addressing them.

Throughout the event, participants were encouraged to share project ideas that could address challenges identified during panel discussions, as well as resources that they could share to solve those challenges. 


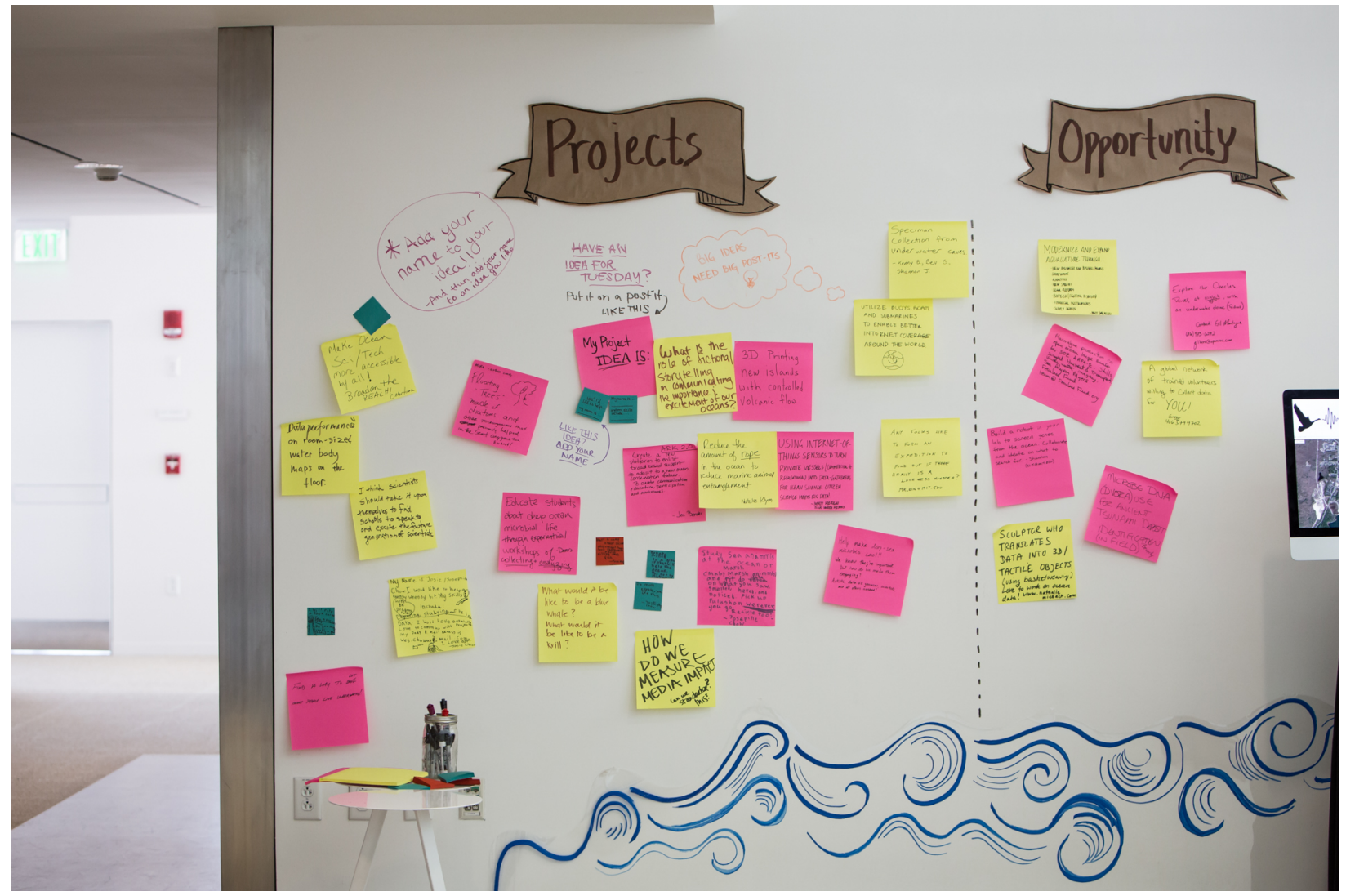

Figure 3

A Projects, Needs, and Opportunies wall was available to participants throughout Here be Dragons to share ideas, resources, and opportunities with other participants.

All panels and lightning talks were streamed live on the MIT Media Lab website as well as a selection of talks on Facebook Live, increasing participation from the 200 inperson attendees to 31,000 around the world (Figure 4). The event had a social media reach of approximately $2 \mathrm{M}$, with nearly $26 \mathrm{M}$ impressions. 
Here be Dragons 2018-02-26

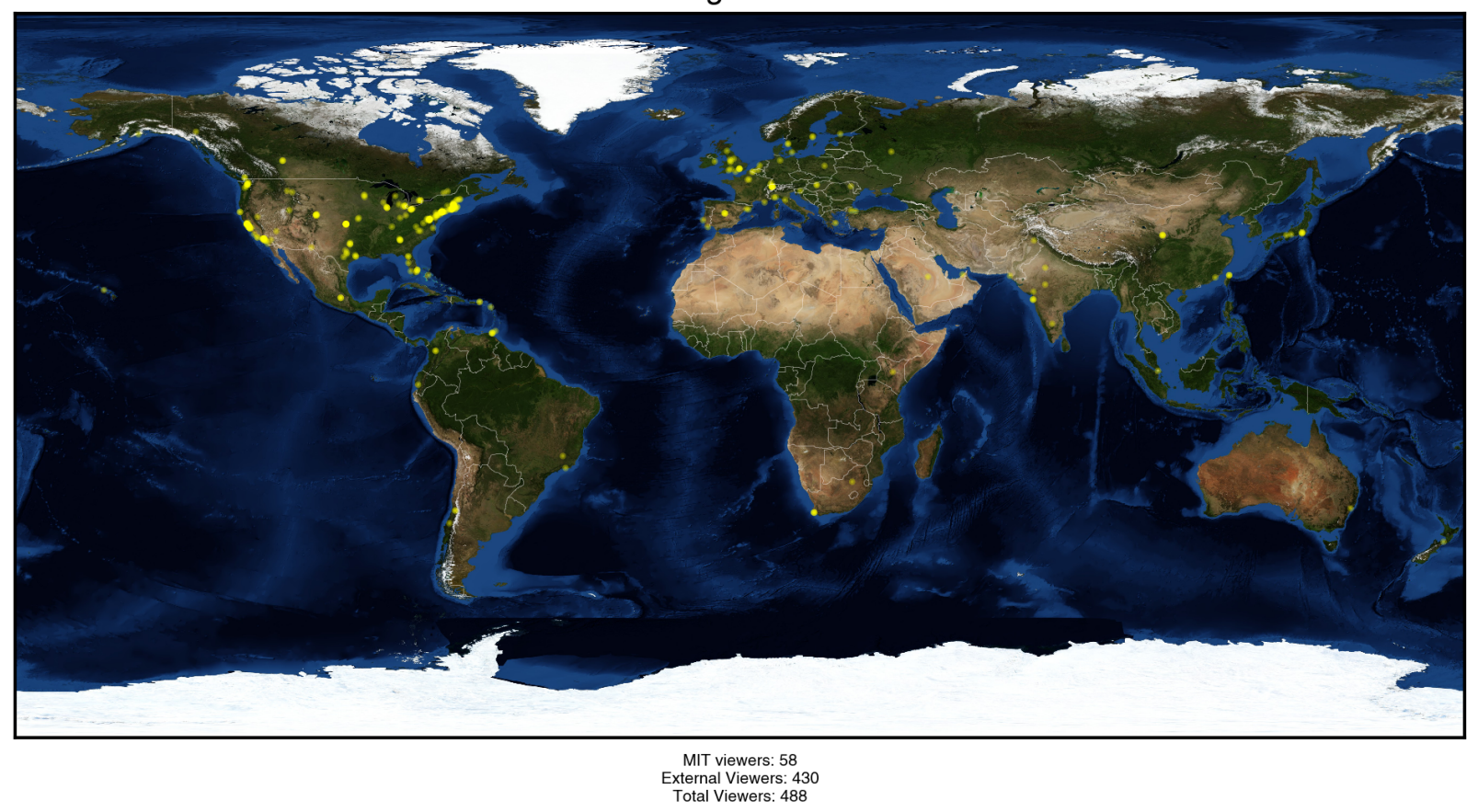

Figure 4

Viewer map shows the locations of 488 individuals around the world live streaming Here be Dragons from the Media Lab website. Facebook Live had a global reach of approximately 31,000.

The first day concluded with a reception and ocean art exhibition, featuring local artists and their multimedia work including Whitney Cornforth's handblown scrimglass, Nathalie Miebach's ocean data sculptures, Mark Adams' paintings, Raquel Fornasaro's paintings and sculptures, among others.
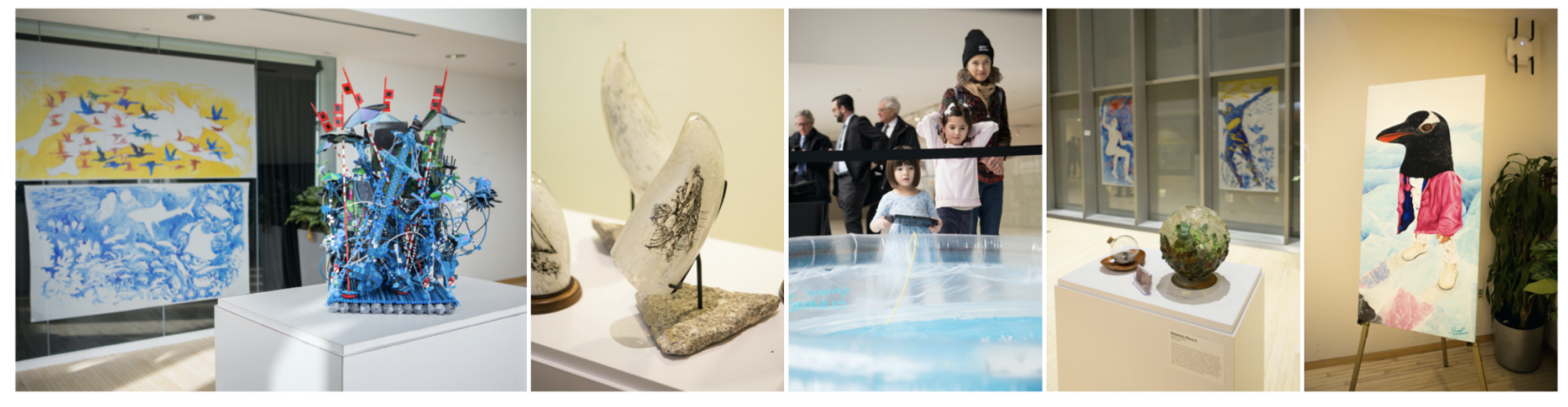


\section{Day 2: Collaborative Project Development}

On the second day, in-person participants broke up into teams for Deeper Dives: Collaborative Project Development to create projects to address challenges in ocean exploration. The teams worked all day to refine their Rapid Field Deployment ideas, and pitched them at the New England Aquarium IMAX Theater that evening. Teams were then required to submit a brief proposal within two weeks of the event. Eight projects were selected for funding, four by NGS and four by Open Ocean. Additional funding was provided to two of the projects by the Inter-American Development Bank and NOAA Office of Ocean Exploration \& Research, both of which participated in the event.

All projects were presented at the 2018 National Ocean Exploration Forum: All Hands on Deck in November 2018, less than a year after their conception.
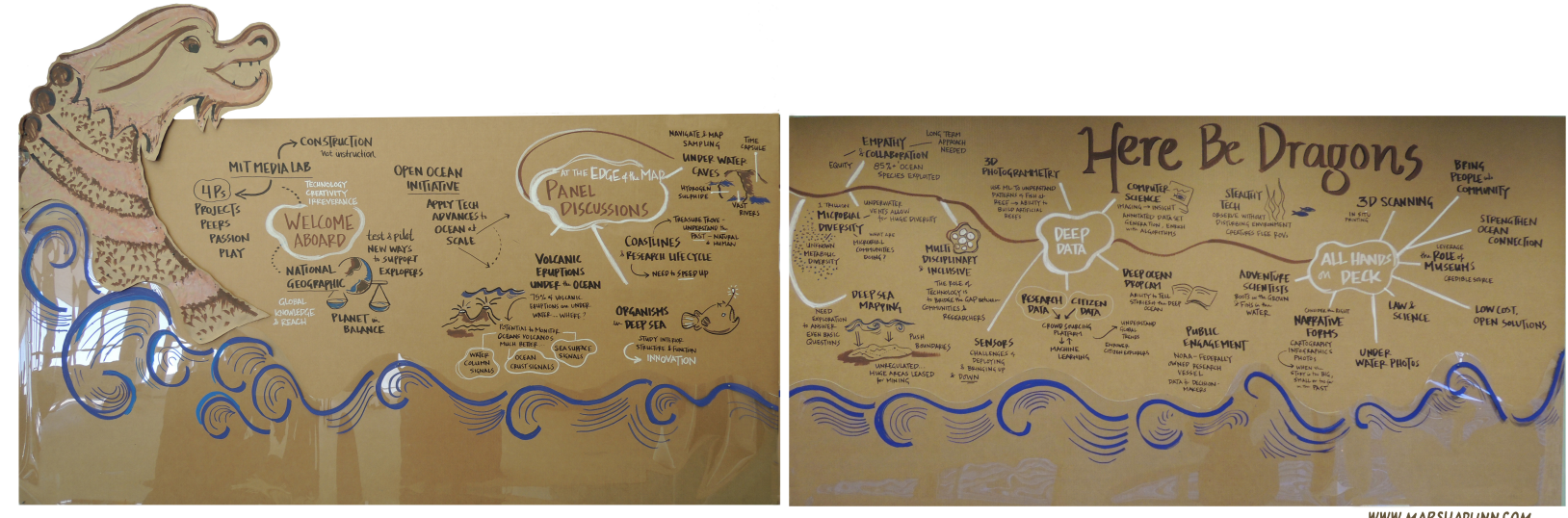

Figure 5

Graphic representation of all panel talks presented at Here be Dragons. Illustration by Marsha Dunn.

\section{Project Selection}

Proposers must have (1) attended Here be Dragons or be affiliated with the MIT Media Lab Open Ocean Initiative, and (2) submitted a draft proposal by March 7, 2018. Thirteen proposals were submitted. Based on the following guidelines and selection criteria, a committee of MIT Media Lab and National Geographic Society representatives recommended eight projects for funding.

\section{Guidelines}

- Projects should aim to move the needle on both better understanding the ocean AND connecting people to it. 
- They should be uniquely suited to the combination of the National Geographic Explorer and MIT communities' common goals of exploring, visualizing, understanding, protecting our ocean environment with creative engineering, technology, and design solutions.

- Projects should be deployed/piloted within 6-9 months. A long-term vision for project continuation is encouraged but not required.

- Results/status presented at the National Ocean Exploration Forum, November 8-10, 2018, at the MIT Media Lab.

\section{Proposal Components}

1. Title

2. Challenge | What challenge are you addressing? Why is it important?

3. Approach | How will you approach the problem innovatively?

4. Unknowns | What are some of the key unknowns?

5. Resources | What resources do you have? What do you need?

6. Timeline | What are your major milestones?

7. Team | Who is on your team? What additional talent do you need?

8. Budget | What level of funding do you need to accomplish your goals?

\section{Evaluation Criteria}

- Innovative | Is the project fresh and forward-looking, leading to previously unachieved outcomes?

- Impactful | Will the project lead to significant impact in ocean understanding and community building?

- Compelling | Will the project broaden an understanding of the challenge that it is trying to solve and engage the public?

- Achievable | Can the project yield practical and concrete results in a realistic time frame? 

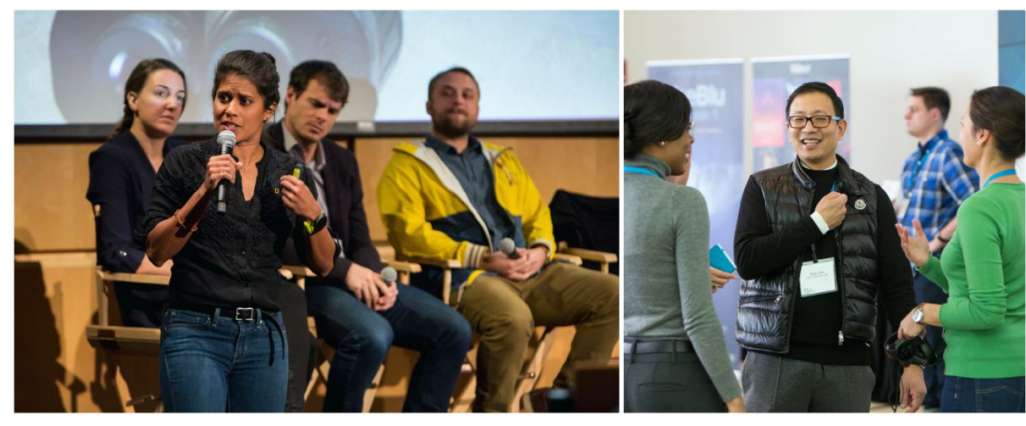

Figure 6

L-R: Dr. Asha de Vos discusses whale poop. Tony Tjan enjoys a moment with other Here be Dragons participants. The event hosted a large contingent of National Geographic ocean explorers.

\section{Funded Projects}

The following are brief descriptions of each funded project that came out of Here be Dragons. Of the eight projects, four are complete and four have continued beyond the initial Rapid Field Deployment phase. For more detailed information, refer to each project report.

\section{Big Ocean, Big Data}

- Goal: establish FathomNet, a new baseline dataset optimized to directly accelerate development of modern, intelligent, automated analysis of underwater visual data.

- Results: FathomNet public release in 2021. Additional funding from numerous sources to continue work. Multiple conference papers and publications (Boulais et al.,2020, Katija et al.,2020, Katija et al.,2019).

- Funded by: National Geographic Society and NOAA Office of Ocean Exploration \& Research

- 2021 status: Continuing

\section{Boston Intertidal Exploration}

- Goal: immerse Boston-area neurodivergent youth in coastal ecosystems to learn about the ecology of rocky and intertidal systems.

- Results: Ran a weekend workshop for Boston neurodivergent youth to understand and explore the intertidal zone; planned and carried out new curriculum based on project.

- Funded by: Open Ocean and National Geographic Society

- 2021 status: Complete 


\section{Connected Coral}

- Goal: create a tangible, at-scale experience telling the story of coral reef bleaching and climate change that can help individuals empathize with the ocean.

- Results: interactive coral reef exhibit on display at the MIT Museum for six months, including during National Ocean Exploration Forum: All Hands on Deck 2018.

- Funded by: Open Ocean

- 2021 status: Complete

\section{Micronauts}

- Goal: invite visitors on a journey into the dynamic world of ocean microbes through an immersive, multisensory experience around cutting-edge scientific discoveries.

- Results: interactive exhibit was displayed at the National Ocean Exploration Forum: All Hands on Deck 2018.

- Funded by: National Geographic Society

- 2021 status: Complete

\section{My Deep Sea, My Backyard}

- Goal: enable Kiribati and Trinidad \& Tobago to explore their own deep-sea backyards using low-cost technology, while building lasting capacity

- Results: workshops were run in Kiribati and Trinidad in 2018; continuous assessment on how best to serve these developing countries through this project; seeking opportunities to expand and scale up the project. Multiple conference papers and publications (Amon et al.,submitted; Bell et al.,2020).

- Funded by: National Geographic Society and Inter-American Development Bank

- 2021 status: Continuing

\section{Ocean Cultures}

- Goal: integrate modern data and indigenous knowledge as a new platform for community-led monitoring of marine microbial ecosystems in New Zealand.

- Results: worked with community of Rongomaiwahine Māori iwi (tribe) in Aeotearoa (New Zealand) who seek to restore native management of watersheds \& fisheries, particularly monitoring of their pāua (abalone) transplantation program.

- Funded by: Open Ocean and National Geographic Society

- 2021 status: Continuing as part of Devora Najjar's doctoral research 


\section{Project Prometheus}

- Goal: develop and deploy a low-cost, high-precision underwater system to quickly and beautifully map caves, coral reefs, and sunken cities.

- Results: cave mapping system developed and field tested.

- Funded by: National Geographic Society

- 2021 status: Continuing

\section{Wheels of Poseidon}

- Goal: generate a living, glowing display built of bioluminescent plankton stimulated by a programmable pattern of pressure waves in the water.

- Results: living display demoed at at the National Ocean Exploration Forum: All Hands on Deck 2018.

- Funded by: Open Ocean

- 2021 status: Complete

\section{Lasting Impact}

The lasting impact of Here Be Dragons extends far beyond the successful projects conceived there. Ocean exploration project initiatives have often been limited to existing academic and exploration institutions, creating a narrow window of potential participants, solutions, and directions. The conversations started at Here Be Dragons involved individuals from numerous disciplines, including oceanography, engineering, art, filmmaking, and design. This juxtaposition of fields not only sparked new ideas, it also created agency among the participants to feel involved in ocean exploration solutions.

The future of ocean exploration, especially deep ocean exploration, will require radical and creative solutions to accelerate the pace of discovery. Ideas will come from all areas of expertise, including telecommunications, robotics, storytelling, visualization, mapping, and more. These individuals had a chance to finally come together to learn, brainstorm, and ideate actual solutions.

Several projects that originated at Here Be Dragons have become substantial programs, including FathomNet, incubated at the Monterey Bay Aquarium Research Institute and launching Sep 30, 2021. This growing dataset of annotated undersea imagery is now used for robotic tracking, as well as live telepresence-based detection

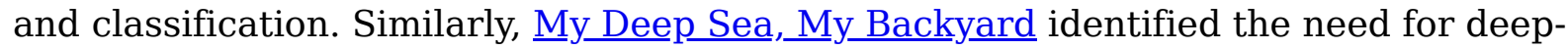
sea capacity building within developing countries and initiated pilot programs and 
solutions that are now growing into a movement within the oceanographic community. The learnings from My Deep Sea also sparked the Global Deep Sea Capacity_ Assessment.

These, and other ideas seeded at Here be Dragons, are the focus of a new non-profit founded in 2021 by Dr. Katy Croff Bell, the Ocean Discovery_League, which aims to remove barriers to the exploration of the deep ocean through the deployment of AIdriven data analysis, low-cost, scalable technologies, and capacity development with historically excluded communities. Here be Dragons launched a new era in ocean exploration-one that is dedicated to the distributed, equitable discovery of the deep sea. With all hands on deck, we will make significantly more progress in understanding our planet than ever before.

\section{Speakers}

\section{Panels}

Morning Plenary

Dr. Katy Croff Bell, MIT Media Lab

Joi Ito, MIT Media Lab

Alex Moen, National Geographic Society

Dr. Robert Ballard, Ocean Exploration Trust 


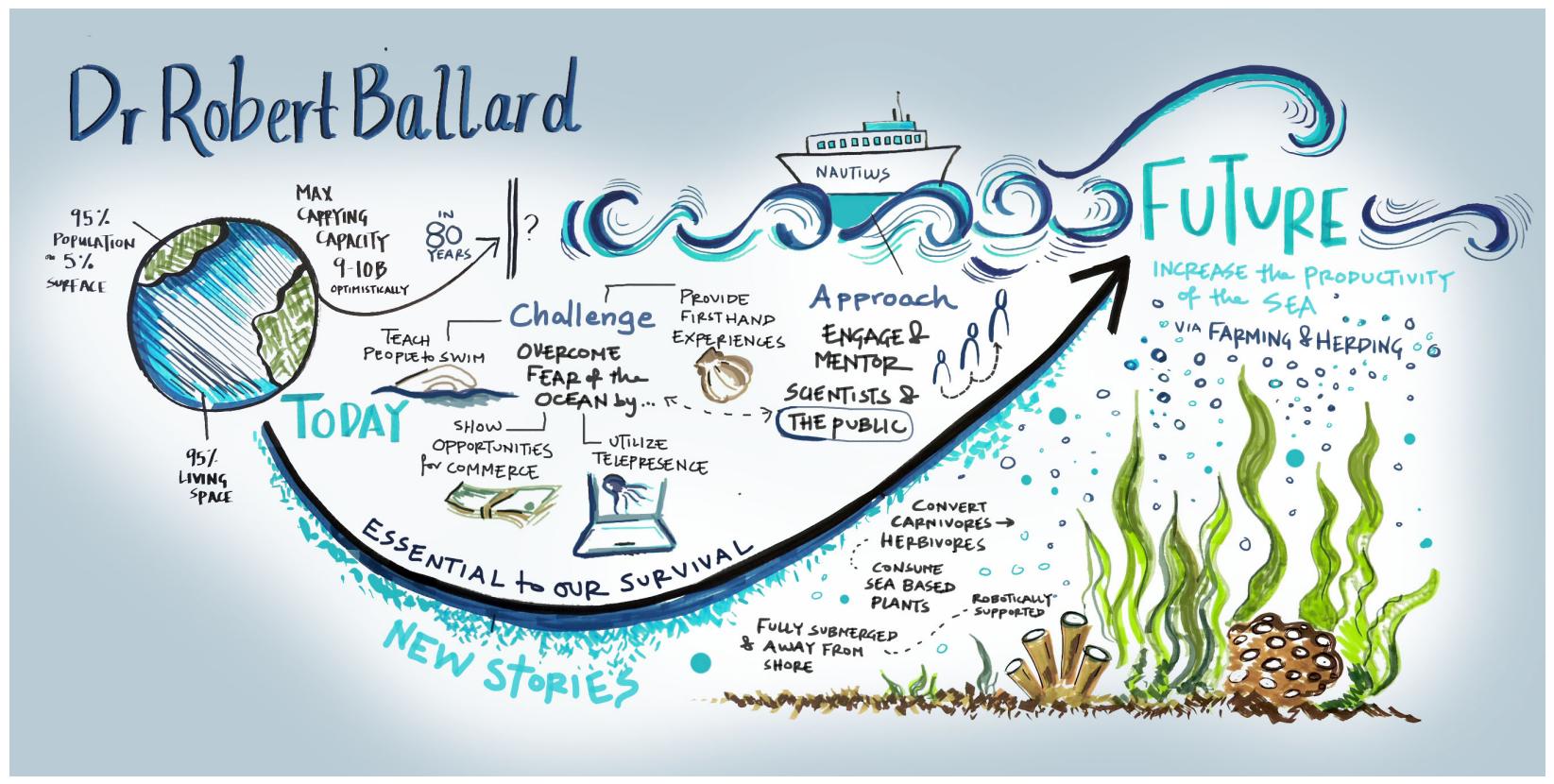

Figure 7

Graphic representation of Dr. Robert Ballard's opening keynote talk at Here be Dragons. Illustration by Marsha Dunn.

At the Edge of the Map A: Exploration and Discovery

Dr. Kenny Broad, Director of the Abess Center for Ecosystem Science and Policy, University of Miami and National Geographic Explorer

Dr. Beverly Goodman, Asst. Professor of Marine Geosciences at the University of Haifa and National Geographic Explorer

Dr. Kakani Katija, Principal Engineer at the Monterey Bay Aquarium Research Institute and National Geographic Explorer

Dr. Adam Soule, Chief Scientist for Deep Submergence at the Woods Hole Oceanographic Institution 


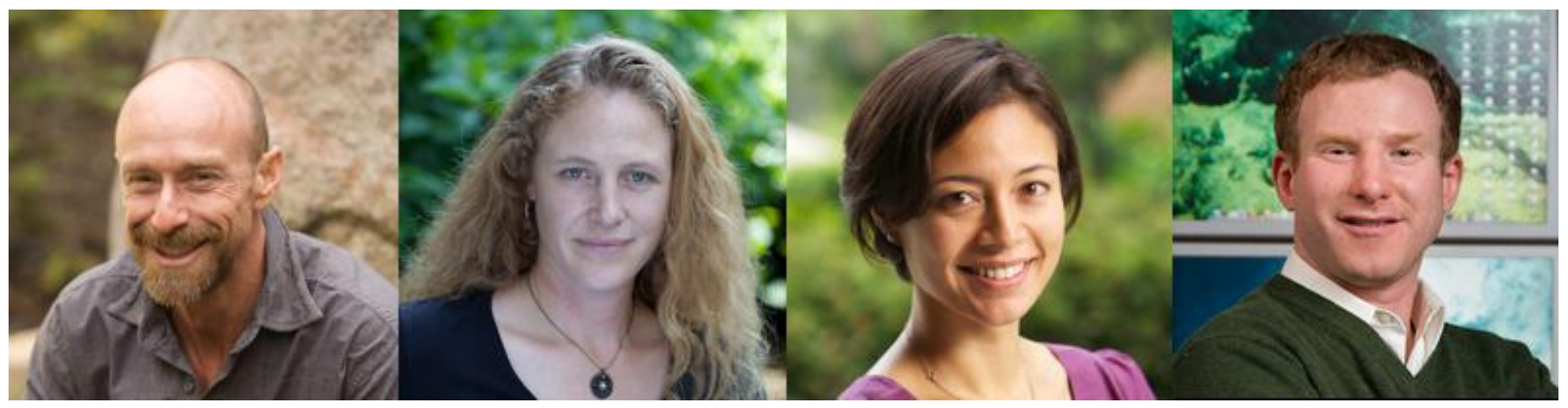

Figure 8

At the Edge of the Map A: Exploration and Discovery. (L-R): Kenny Broad, Bererly Goodman, Kakani Katija, Adam Soule

\section{At the Edge of the Map B: Our Thriving Ocean}

Dr. Diva Amon, Marie Skłodowska-Curie research fellow at the Natural History Museum, London

Dr. Ayana Elizabeth Johnson, marine biologist, policy expert, and founder of Ocean Collectiv

Dr. John Mandelman, Vice President and Chief Scientist of the Anderson Cabot Center at the New England Aquarium

Dr. Jeff Marlow, geobiologist at Harvard University and National Geographic Explorer

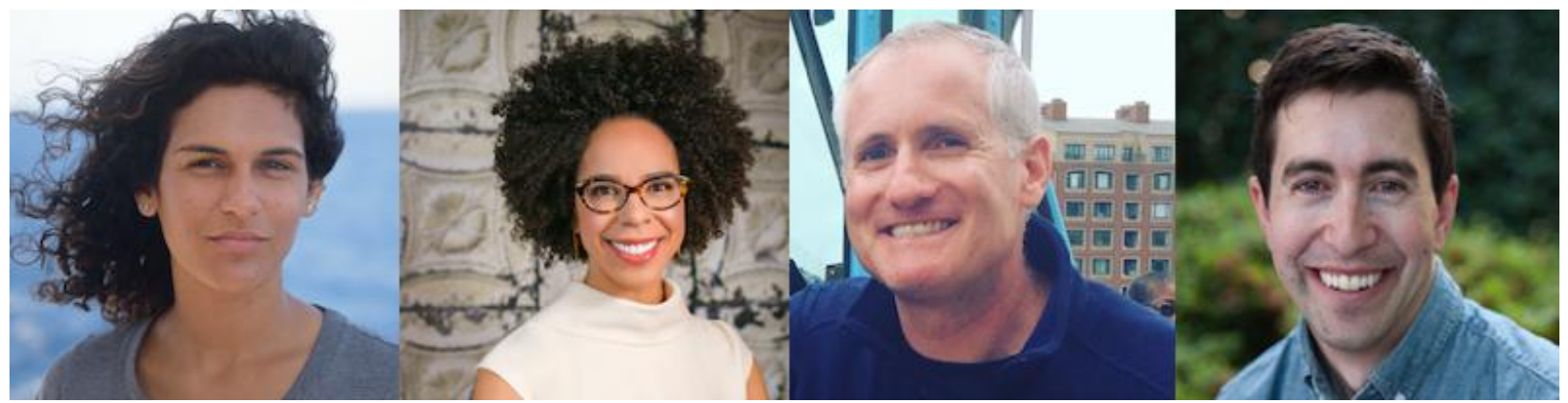

Figure 9

At the Edge of the Map B: Our Thriving Ocean. (L-R): Diva Amon, Ayana Elizabeth Johnson, John Mandelman, Jeff Marlow

Deep Data A: Analysis and Sharing

Dr. Katy Croff Bell '00, Founder and Director of the MIT Media Lab Open Ocean Initiative and National Geographic Explorer

Alan Turchik, Product Development Manager for the Exploration Technology Lab at the National Geographic Society 
Ben Woodward, Co-Founder of CVision AI

Grace Calvert Young '14, aquanaut, PhD Candidate at University of Oxford, and National Geographic Explorer

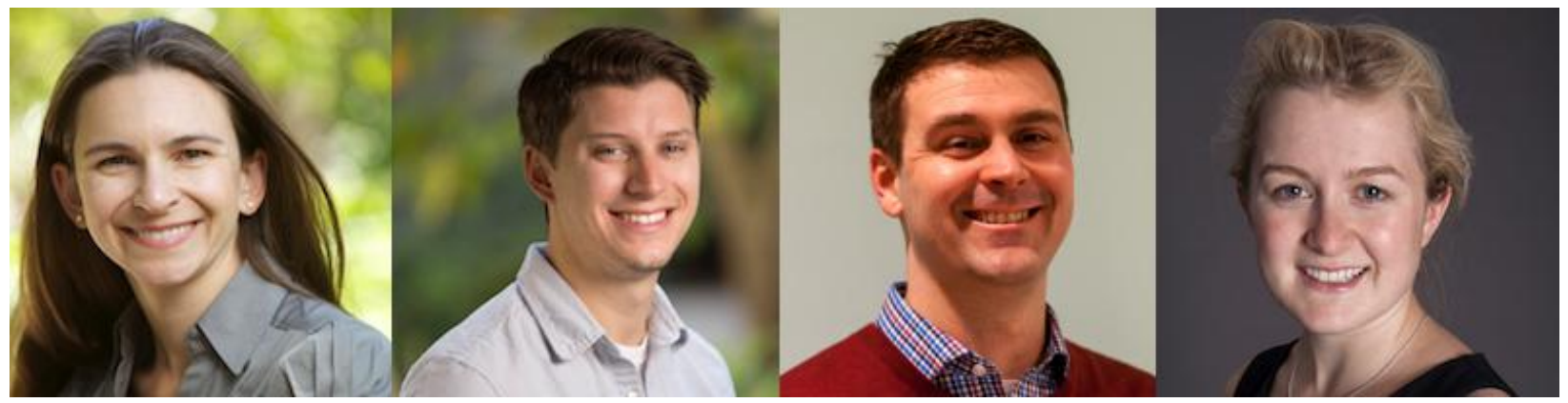

Figure 10

Deep Data A: Analysis and Sharing. (L-R): Katy Croff Bell, Alan Turchik, Ben Woodward, Grace Calvert Young

Deep Data B: Platforms and Sensors

Dr. Alan Leonardi, Director of the NOAA Office of Ocean Exploration and Research Dr. Anna Michel '98, SM'02, PhD'07, Associate Scientist at the Woods Hole Oceanographic Institution

Dr. Brennan Phillips, Professor of Ocean Engineering at the University of Rhode Island and National Geographic Explorer

Antonella Wilby, PhD student studying Computer Science at the University of California, San Diego, and National Geographic Explorer

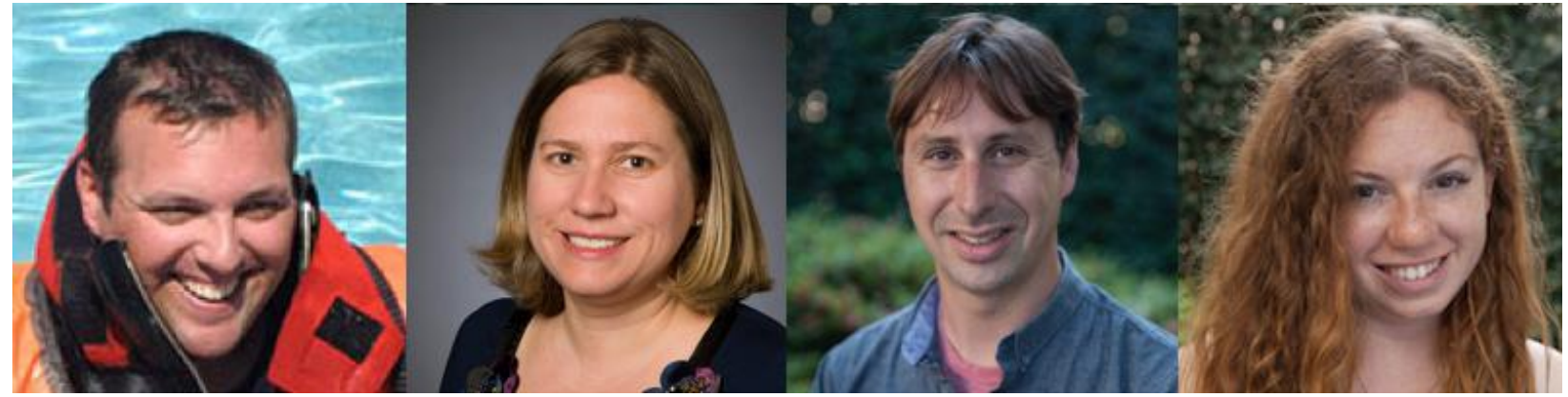

Figure 11

Deep Data B: Platforms and Sensors. (L-R): Alan Leonardi, Anna Michel, Brennan Phillips, Antonella Wilby 


\section{All Hands on Deck A: Sea Stories}

Corey Jaskolski SM'02, Founder of Hydro Technologies and National Geographic Explorer

Susan Poulton, Chief Digital Officer of The Franklin Institute Brian Skerry, photojournalist and National Geographic Explorer

Kaitlin Yarnall, Vice President of Media Innovation at the National Geographic Society

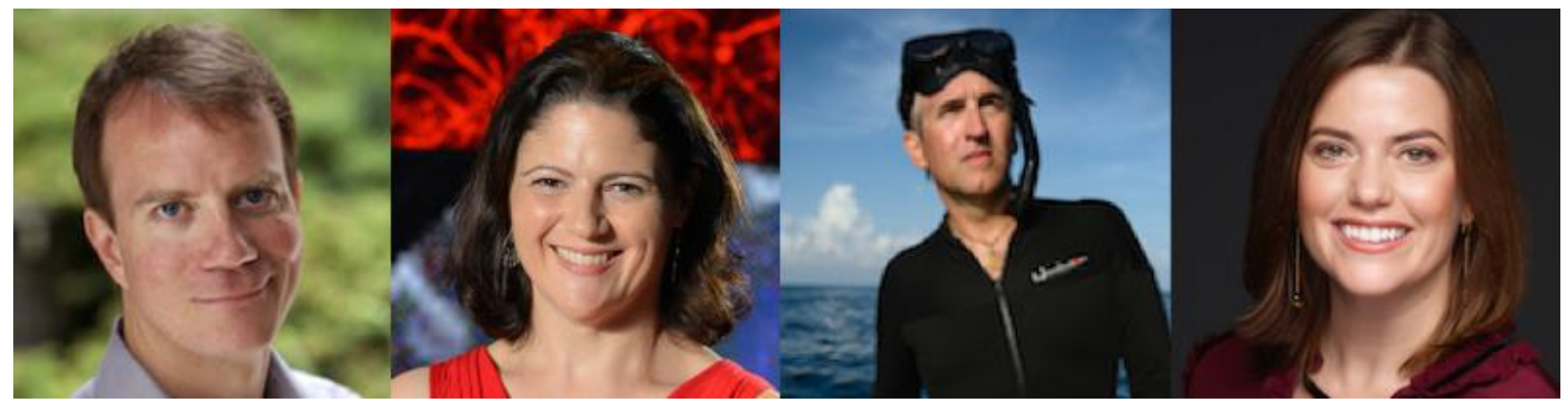

Figure 12

All Hands on Deck A: Sea Stories. (L-R): Corey Jaskolski, Susan Poulton, Brian Skerry, Kaitlin Yarnall

\section{All Hands on Deck B: Democratizing the Ocean}

Annie Brett, lawyer and PhD candidate at the University of Miami

Dr. Asha de Vos, Sri Lankan ocean educator and founder of Oceanswell and National Geographic Explorer

Shah Selbe, conservation technologist, founder of Conservify and National Geographic Explorer

Gregg Treinish, founder and Executive Director of Adventure Scientists, and National Geographic Explorer 


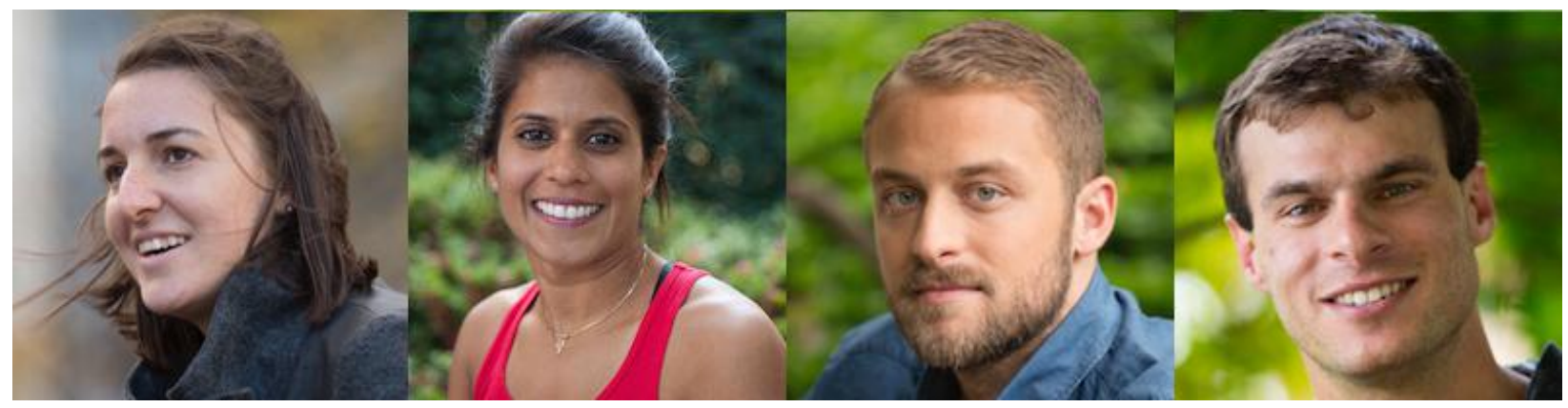

Figure 13

All Hands on Deck B: Democratizing the Ocean. (L-R) Annie Brett, Asha de Vos, Shah Selbe, Gregg Treinish

\section{Afternoon Plenary}

Tim Delaney, Imagineer

Sara Drakeley '12, software engineer for Engineers Gate

Dan Novy, PhD student at the MIT Media Lab
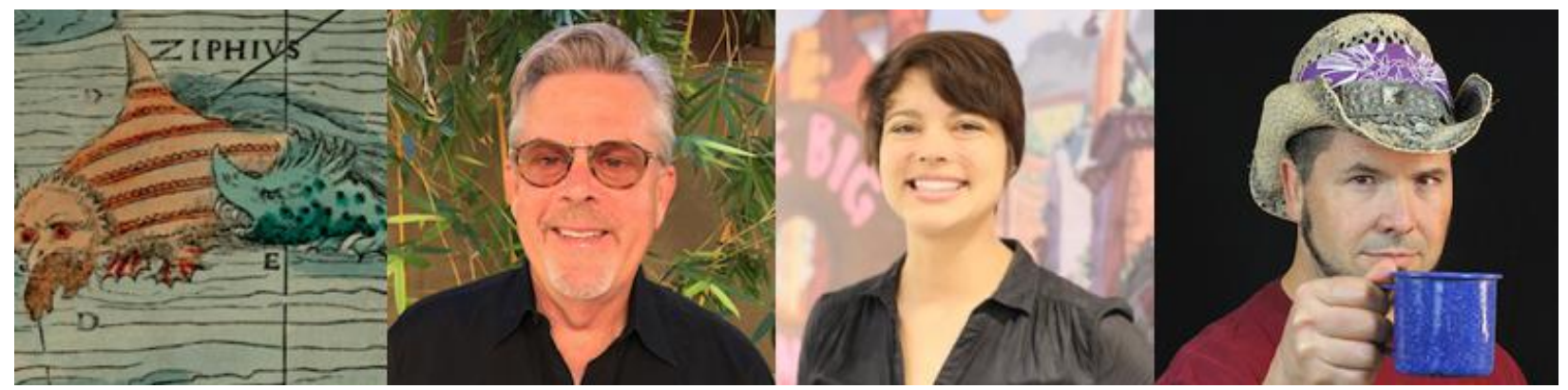

Figure 14

Afternoon Plenary. (L-R) Ziphius, Tim Delaney, Sara Drakeley, Dan Novy 


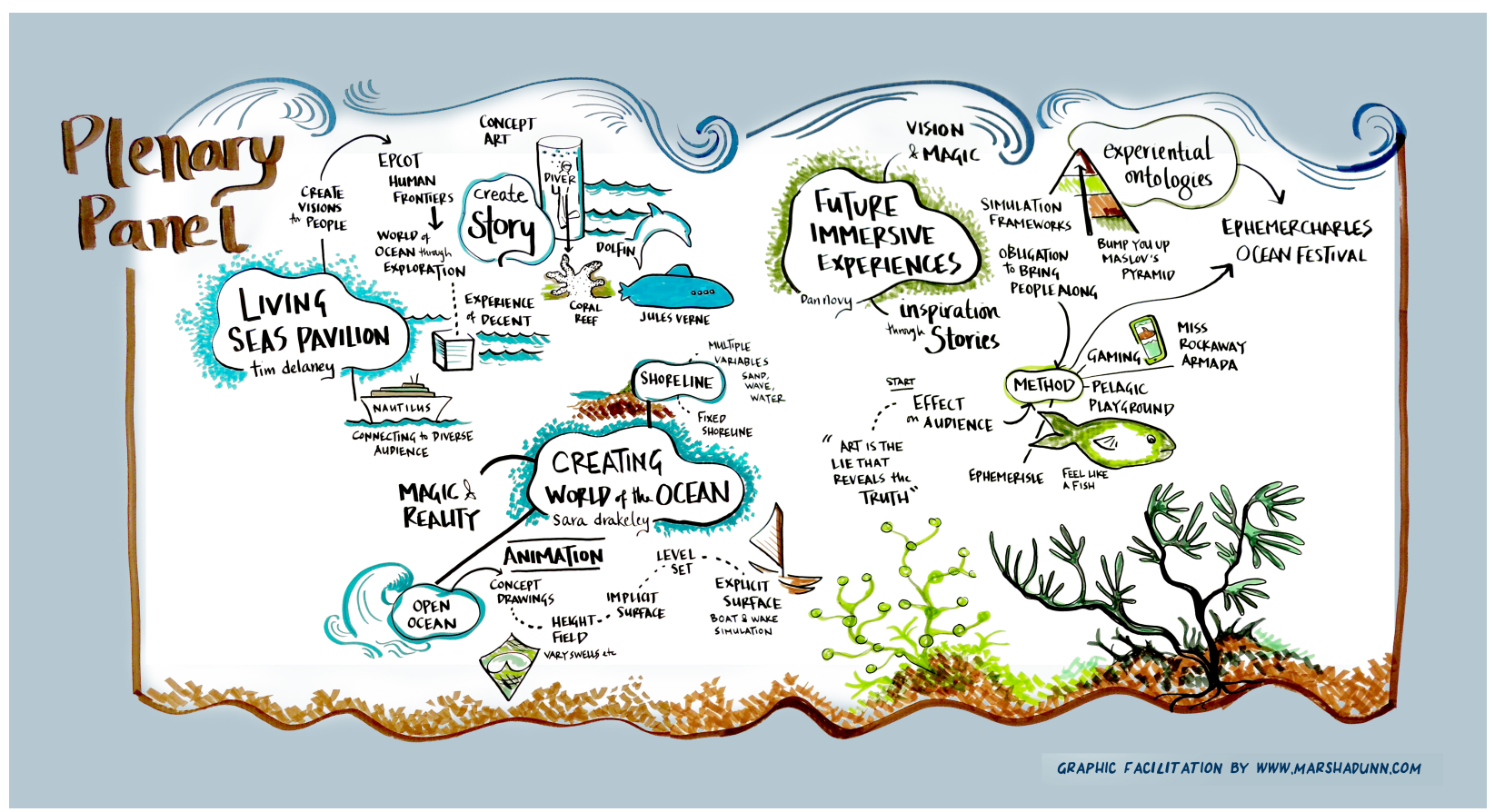

Figure 15

Graphic representation of closing plenary panel at Here be Dragons, focused on storytelling and immersive experiences. Illustration by Marsha Dunn.

\section{Moderators}

Dr. V. Michael Bove, MIT Media Lab Object-Based Media

Dr. Peter Girguis, Professor of Organismic \& Evolutionary Biology at Harvard University

Dr. Andrew Lippman, MIT Media Lab Viral Communications

Devora Najjar, graduate student, MIT Media Lab

Dr. Dava Newman SM'89, SM'89, PhD'92, Apollo Professor of Astronautics at MIT and former NASA Deputy Administrator

Dr. Joe Paradiso, MIT Media Lab Responsive Environments

Brooke Runnette, Chief Program Officer of Emerson Elemental 


\section{Lightning Talks}
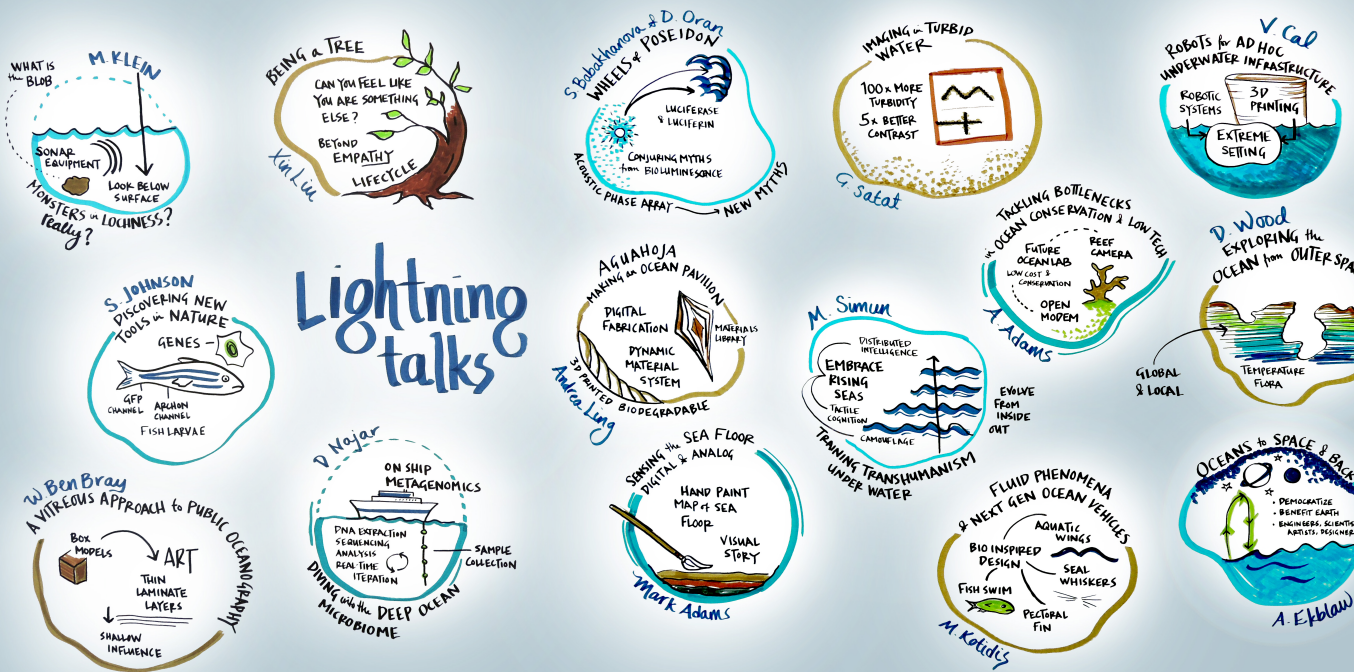

Figure 16

Graphic representation of first half of Here be Dragons Lightning Talks. Illustration by Marsha Dunn.

Monsters in Loch Ness? Really? | Martin Klein '62, Martin Klein Consultants

Discovering New Tools from Nature | Shannon Johnson, Synthetic

Neurobiology, MIT Media Lab

Diving into the Deep Ocean Microbiome | Devora Najjar, Sculpting Evolution, MIT Media Lab

Sensing the sea floor in analog and digital, knots and waveforms | Mark Adams, Center for Coastal Studies

Aguahoja: Making an Ocean Pavilion | Andrea Ling, Mediated Matter, MIT Media Lab

Being A Tree | Xin Liu, Space Exploration Initiative, MIT Media Lab

Wheels of Poseidon | Siranush Babakhanova and Daniel Oran, Synthetic Neurobiology, MIT Media Lab

A Vitreous Approach to Public Oceanography | Ben Bray, MIT Sea Grant 
Training Transhumanism Underwater | Miriam Simun, Design Fiction, MIT Media $\mathrm{Lab}$

Tackling Bottlenecks in Ocean Conservation with Low-cost Tech | Allan Adams MIT Future Oceans Lab

Imaging in Turbid Water | Guy Satat, Camera Culture, MIT Media Lab

Understanding Fluid Phenomena and Designing the Next Generation of Ocean Vehicles | Miranda Kotidis, MIT Towing Tank

Robots for Ad-hoc Underwater Infrastructure | Veevee Cai, Mediated Matter, MIT Media Lab

Exploring the Ocean from Space | Danielle Wood, Space Enabled, MIT Media $\mathrm{Lab}$

Sister Initiatives - From Oceans to Space, and back! | Ariel Ekblaw, Space Exploration Initiative and Responsive Environments, MIT Media Lab

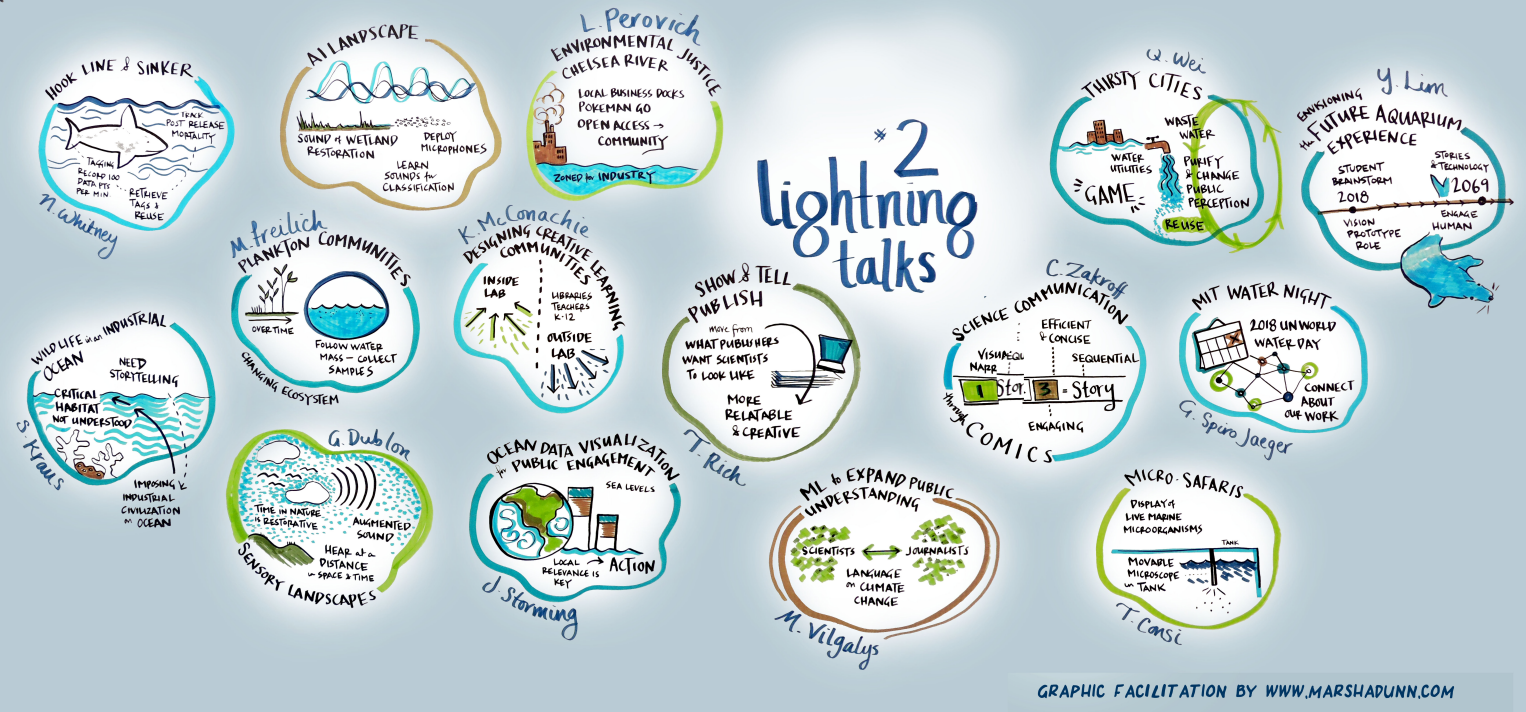

Figure 17

Graphic representation of second half of Here be Dragons Lightning Talks. Illustration by Marsha Dunn.

Hook, line, and sinker? New tech to study the life and death of sharks | Nick Whitney, Anderson Cabot Center for Ocean Life, New England Aquarium 
Wildlife in an Industrial Ocean | Scott Kraus, Anderson Cabot Center for Ocean Life, New England Aquarium

Meandering routes of plankton communities | Mara Freilich, MIT/WHOI Joint Program

AI Landscapes: Computing the Sound of Wetland Restoration | Clement Duhart, Responsive Environments, MIT Media Lab

Sensory Landscapes: Extended Intelligence and a New Ecological Sensibility | Gershon Dublon, Responsive Environments, MIT Media Lab

Designing Creative Learning Communities | Katherine McConachie, Learning Initiative, MIT Media Lab

Pokemon Go, pH, and projectors: environmental justice and the Chelsea River | Laura Perovich, Object-based Media, MIT Media Lab

Ocean Data Visualization for Citizen Engagement | Jeremy Stroming, MIT Department of Aeronautics and Astronautics

Machine Learning to Expand Public Understanding of Climate Science | Max Vilgalys, MIT Institute for Data, Systems, and Society

Show and Tell and Publish | Travis Rich, Viral Communications, MIT Media Lab

Science and Comics: Sequential Visual Narratives | Casey Zakroff, MIT/WHOI Joint Program

Thirsty Cities | Quantum Wei, MIT Water Club

MIT Water Night | Gualtiero Spiro Jaeger, MIT Water Club

Micro-Safaris: The Display of Live Marine Microorganisms at Public Aquariums | Thomas Consi, MIT Sea Grant

Reimagining the Future Aquarium : NEAQ 2069 | Yihyun Lim, MIT Design $\mathrm{Lab}$

\section{Citations}

1. Boulais O., B. Woodward, L. Lundsten, K. Barnard, B. Schlining, K.L.C. Bell, K. Katija. 2020. FathomNet: An underwater image training database for ocean 
exploration and discovery. arXiv: 2007.00114.

2. Katija, K., B. Woodward, B. Schlining, L. Lundsten, K. Barnard, K.L.C. Bell. 2020. Towards an open, underwater image repository (FathomNet) for automated detection and classification of midwater and benthic targets using machine learning. Ocean Sciences Meeting, IS31A-05. San Diego, CA. $\_$

3. Katija, K., B. Woodward, L. Lundsten, B. Schlining, K. Barnard, K.L.C. Bell. 2019. FathomNet: An open, underwater image repository for automated detection and classification of midwater and benthic targets using machine learning. Marine Imaging Workshop 2019. Victoria, British Columbia. $\_$

4. Amon, D.J., R.R. Rotjan, B.R.C. Kennedy, G. Alleng, R. Anta, E. Aram, K.M. Gjerde, J. Gobin, T. Edwards, M. Ford-Creary, L-A. Henderson, R. Hinds, A. Hope, B. Phillips, R.K. Ali, S. Lanser, K. Lewis, H. Lochan, S. MacLean, N. Mwemwenikarawa, B. Rimon, S-A. Sarjursingh, A. Tekiau, T. Teemari, A. Turchik, H. Vallès, K. Waysang, K.L.C. Bell. Submitted. My Deep Sea, My Backyard: A Pilot Study to Build Capacity for Global Deep-Ocean Exploration and Research. Philosophical Transactions of the Royal Society $B . \sqcup$

5. Bell, K.L.C., R. Rotjan, D. Amon, B. Kennedy, B. Phillips \& A. Turchik. 2020. My Deep Sea, My Backyard: Building Deep Sea Capacity in Big Ocean Developing States. Ocean Sciences Meeting, IS31A-05. San Diego, CA. $\_$ 